\title{
DESIGN OF TCSC-BASED CONTROLLER USING PARTICLE SWARM OPTIMIZATION ALGORITHM
}

\author{
A. K. Baliarsingh, D. P. Dash, N. R. Samal, S. Panda. \\ Department of Electrical Engineering, Orissa Engineering College, Bhubaneswar, Orissa, India \\ Department of Electrical and Electronics Engineering, VSSUT Burla, Orissa, India
}

\begin{abstract}
Design of an optimal controller requires optimization performance measures that are often noncommensurable and competing with each other. Design of such a controller is indeed a particle swarm optimization (PSO) problem. This paper investigates the comparison of application of PSO based optimization technique and Differential Evolution (DE) for the design of a Thyristor Controlled Series Compensator (TCSC)-based supplementary damping controller. The design objective is to improve the power system stability with minimum control effort. The proposed technique is applied to generate of global optimal solutions to the given optimization problem. Simulation results are presented to show the effectiveness and robustness of the proposed approach.
\end{abstract}

Keywords:- particle swarm optimization algorithm, thyristor controlled series compensator, power system stabilityand Differential Evolutio

\section{INTRODUCTION:}

Series capacitive compensation was introduced decades ago to cancel a portion of the reactive line impedance and thereby increase the transmittable power. Subsequently, within the FACTS initiative, it has been demonstrated that variable series compensation is highly effective in both controlling power flow in the lines and in improving stability. Thyristor Controlled Series Compensator (TCSC) is one of the important members of FACTS family that is increasingly applied with long transmission lines by the utilities in modern power systems. It can have various roles in the operation and control of power systems, such as scheduling power flow; decreasing unsymmetrical components; reducing net loss; providing voltage support; limiting short-circuit currents; mitigating sub synchronous resonance; damping the power oscillation and enhancing transient stability.

Several modern heuristic tools have evolved in the last two decades that facilitates solving optimization problems that were previously difficult or impossible to solve. Among these heuristic techniques, Genetic Algorithm (PSO) and Differential Evolution (DE) techniques appeared as promising algorithms for handling the optimization problems. These techniques are finding popularity within research community as design tools and problem solvers because of their versatility and ability to optimize in complex multimodal search spaces applied to nondifferentiable objective functions.

In this paper to study the dynamic performance of DE and PSO optimized TCSC-based controller subjected to different disturbances over a wide range of loading conditions and parameter variations.

\section{STRUCTURE OF THE TCSC CONTROLLER:}

The commonly used lead-lag structure is chosen in this study as a TCSC-based controller. The structure of the TCSC controller is shown in Fig. 2. It consists of a gain block with gain $K_{T}$, a signal washout block and two-stage phase compensation block. The phase compensation block provides the appropriate phase-lead characteristics to compensate for the phase lag between input and the output signals. The signal washout block serves as a high-pass filter, with the time constant $T_{W T}$, high enough to allow signals associated with oscillations in input signal to pass unchanged. Without it steady changes in input would modify the output. From the viewpoint of the washout function, the value of $T_{W T}$ is not critical and may be in the range of 1 to 20 seconds.

The damping torque contributed by the TCSC can be considered to be in two parts. The first part $K_{P}$, which is referred as the direct damping torque, is directly

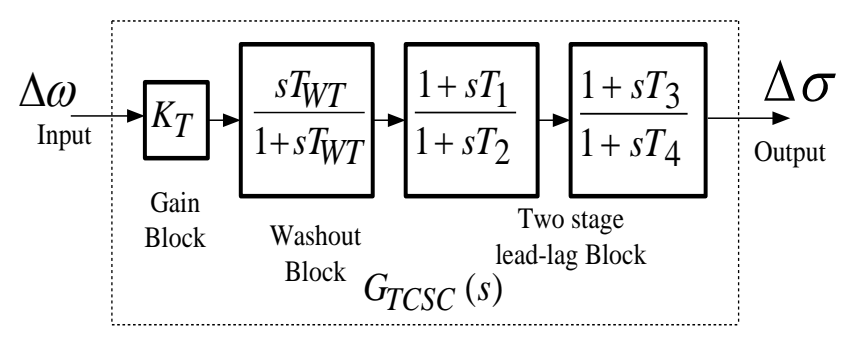

Fig. 1 Structure of the TCSC controller 
applied to the electromechanical oscillation loop of the generator. The second part $K_{Q}$ and $K_{V}$, named as the indirect damping torque, applies through the field channel of the generator.

\section{OBJECTIVE FUNCTION:}

It is worth mentioning that the TCSC-based controller is designed to minimize the power system oscillations after a disturbance so as to improve the stability. These oscillations are reflected in the deviation in the generator rotor speed $(\Delta \omega)$. In the present study, an integral time absolute error of the speed deviations is taken as the objective function $J$, expressed as:

$$
J=\int_{t=0}^{t=t_{1}}|\Delta \omega| \cdot t \cdot d t
$$

In the above equations, $|\Delta \omega|$ is the absolute value of the speed deviation and $t_{1}$ is the time range of the simulation. With the variation of $K_{T}, T_{1 T}, T_{3 T}$, the TCSC-based controller parameters, $J$ will also be changed. For objective function calculation, the time-domain simulation of the power system model is carried out for the simulation period. It is aimed to minimize this objective function in order to improve the system response in terms of the settling time and overshoots.

\section{APPLICATION AND COMPARISON OF PSO AND DE:}

PSO has been used for optimizing the parameters of control system that are complex and difficult to solve by conventional optimization methods. Implementation of PSO requires the determination of six fundamental issues: chromosome representation, selection function, the genetic operators, initialization, termination and evaluation function. Various types of representations of an individual or chromosome are: binary digits, floating point numbers, integers, real values, matrices, etc. Similarly, there are several schemes for the selection process: roulette wheel selection and its extensions, scaling techniques, tournament, normal geometric, elitist models and ranking methods.

Differential Evolution (DE) algorithm is a stochastic, population-based optimization algorithm recently introduced [18]. DE works with two populations; old generation and new generation of the same population. The size of the population is adjusted by the parameter $N_{P}$. The population consists of real valued vectors with dimension $D$ that equals the number of design parameters/control variables. The population is randomly initialized within the initial parameter bounds. The optimization process is conducted by means of three main operations: mutation, crossover and selection. In each generation, individuals of the current population become target vectors. For each target vector, the mutation operation produces a mutant vector, by adding the weighted difference between two randomly chosen vectors to a third vector. The crossover operation generates a new vector, called trial vector, by mixing the parameters of the mutant vector with those of the target vector. If the trial vector obtains a better fitness value than the target vector, then the trial vector replaces the target vector in the next generation. Optimization process is repeated 20 times for both PSO and DE.

Table 1. Comparison of results for 20 runs of particle swarm optimization and DE

\begin{tabular}{|l|l|l|}
\hline Values & DE & PSO \\
\hline Best & 1.74722 & 1.74724 \\
Average & 1.75135 & 1.80279 \\
Worst & 1.76554 & 1.85946 \\
Standard deviation & 0.00433 & 0.03504 \\
\hline
\end{tabular}

Table 2. Best solution for TCSC controller in 20 runs of DE and PSO

\begin{tabular}{|l|l|l|l|}
\hline \multirow{2}{*}{ Technique } & \multicolumn{3}{|l|}{ TCSC-based controller parameters } \\
\cline { 2 - 4 } & $K_{T}$ & $T_{I T}$ & $T_{3 T}$ \\
\hline DE & 62.5107 & 0.1176 & 0.1111 \\
PSO & 63.5247 & 0.1134 & 0.1163 \\
\hline
\end{tabular}

\section{DYNAMIC PERFORMANCE OF DE AND PSO FOR TCSC-BASED CONTROLLER:}

To evaluate the capability of the DE and PSO optimized TCSC-based controllers on damping electromechanical oscillations of the example electric power system, simulations are carried out. To assess the effectiveness and robustness of the controllers, different loading conditions and parameters variations as given in Table 3 are considered.

Table 3 Loading conditions and parameter variations

\begin{tabular}{|l|l|}
\hline $\begin{array}{l}\text { Loading condition } \\
(\boldsymbol{P}, \boldsymbol{Q}) \mathbf{p u}\end{array}$ & Parameter variation \\
\hline Nominal $(0.9,0.469)$ & $\begin{array}{l}\text { No parameter variation } \\
\text { Light }(0.4,0.1446)\end{array}$ \\
$\begin{array}{l}50 \% \text { increase in line } \\
\text { reactance }\end{array}$ \\
Heavy $(1.02,0.5941)$ & $\begin{array}{l}10 \% \text { decrease in line } \\
\text { reactance and } \\
5 \% \text { increase in terminal } \\
\\
\text { voltage }\end{array}$ \\
\hline
\end{tabular}


IOSR Journal of Engineering

Apr. 2012, Vol. 2(4) pp: 810-813

Table 4 System eigenvalues without and with control at nominal loading

\begin{tabular}{|l|l|l|l|}
\hline $\begin{array}{l}\text { Without } \\
\text { control }\end{array}$ & $\begin{array}{l}\text { With } \\
\text { CPSS }\end{array}$ & $\begin{array}{l}\text { With } \\
\text { DETCSC }\end{array}$ & $\begin{array}{l}\text { With } \\
\text { PSOTCSC }\end{array}$ \\
\hline$+0.2681 \pm$ & -0.9043 & $-4.7908 \pm$ & $-4.7587 \pm$ \\
$4.9487 \mathrm{i}$ & $\pm 4.6902 \mathrm{i}$ & $2.5761 \mathrm{i}$ & $2.3606 \mathrm{i}$ \\
$-10.3053 \pm$ & -5.1452 & $-6.6967 \pm$ & $-6.776 \pm$ \\
$1.19529 \mathrm{i}$ & $\pm 6.2315 \mathrm{i}$ & $2.9764 \mathrm{i}$ & $3.1735 \mathrm{i}$ \\
- & -17.9725 & -17.7925 & -18.0247 \\
- & - & -9.2013 & -9.1299 \\
- & - & -0.1039 & -0.1039 \\
\hline
\end{tabular}

Table 6. System eigenvalues without and with control at heavy loading

\begin{tabular}{|l|l|l|l|}
\hline $\begin{array}{l}\text { Without } \\
\text { control }\end{array}$ & $\begin{array}{l}\text { With } \\
\text { CPSS }\end{array}$ & With DETCSC & $\begin{array}{l}\text { With } \\
\text { PSOTCSC }\end{array}$ \\
\hline+0.2879 & -1.1251 & $-5.627 \pm$ & $-5.7335 \pm$ \\
$\pm 5.3194 \mathrm{i}$ & \pm & $4.3346 \mathrm{i}$ & $0.8472 \mathrm{i}$ \\
& $5.1439 \mathrm{i}$ & & $-5.7988 \pm$ \\
-10.3239 & -4.8094 & - & $4.3217 \mathrm{i}$ \\
$\pm 1.5872 \mathrm{i}$ & $\pm 6.141 \mathrm{i}$ & $5.8523 \pm 0.8676 \mathrm{i}$ & -18.7092 \\
- & - & -18.4654 & \\
- & 18.2002 & & -9.0826 \\
\hline
\end{tabular}

Table 5. System eigenvalues without and with control at light loading

\begin{tabular}{|l|l|l|l|}
\hline $\begin{array}{l}\text { Without } \\
\text { control }\end{array}$ & $\begin{array}{l}\text { With } \\
\text { CPSS }\end{array}$ & $\begin{array}{l}\text { With } \\
\text { DETCSC }\end{array}$ & $\begin{array}{l}\text { With } \\
\text { PSOTCSC }\end{array}$ \\
\hline$+0.0445 \pm$ & $-0.4842 \pm$ & $-2.8435 \pm$ & $-2.8529 \pm$ \\
$4.7285 \mathrm{i}$ & $4.6163 \mathrm{i}$ & $2.8435 \mathrm{i}$ & $2.7923 \mathrm{i}$ \\
$-10.0864 \pm$ & $-6.6916 \pm$ & $-9.9944 \pm$ & $-9.9944 \pm$ \\
$3.4026 \mathrm{i}$ & $5.4432 \mathrm{i}$ & $3.3918 \mathrm{i}$ & $3.396 \mathrm{i}$ \\
- & -15.7307 & -14.4264 & -14.6947 \\
- & -0.3349 & -9.4266 & -9.3828 \\
- & - & -0.1034 & -0.1035 \\
\hline
\end{tabular}

\section{CONCLUSIONS}

The significant contributions of the research work presented in this chapter are:

1. A systematic approach for designing a TCSC-based controller employing modern heuristic optimization techniques (PSO and DE) has been presented. It is observed that, in terms of computational time, the PSO

approach is faster. However, the DE converges in fewer generations than the PSO.

2. Studies show that the proposed controllers are robust and perform satisfactorily under various disturbances at wide ranges of loading conditions with parameter variations.

\section{REFERENCES}

[1] P. Kundur, Power System Stability and Control. New York: McGraw-Hill, 1994.

[2] N. G. Hingorani, L. Gyugyi, Understanding FACTS: Concepts and Technology of Flexible AC Transmission Systems, IEEE Press, New York, 2000.

[3] Y. H Song, T. A. Johns, Flexible AC Transmission Systems (FACTS), IEE, London, 2000.

[4] R. M Mathur, R. K. Verma, Thyristor-based FACTS Controllers for Electrical Transmission Systems, IEEE Press, Piscataway, 2002.

[5] L Gyugyi. 'Unified Power Flow Control Concept for Flexible ac Transmission Systems.' IEE ProceedingsC, Vol. 139, No 4, pp. 323-331, 1992.

[6] L. Gyugyi et. al., "The Unified Power Flow Controller: A New Approach to Power Transmission Control", IEEE Trans. Power Delv. Vol. 10, No. 2, pp. 10851093, 1995.

[7] Sidhartha Panda, "Application of non-dominated sorting genetic algorithm-II technique for optimal FACTS-based controller design", Journal of the Franklin Institute, doi:10.1016/j.jfranklin.2010.03.013.

[8] Sidhartha Panda, S.C. Swain, P.K. Rautray, R. Mallik, G. Panda, "Design and analysis of SSSC-based supplementary damping controller", Simulation Modelling Practice and Theory, doi: 10.1016/j.simpat.2010.04.007.

[9] Sidhartha Panda, "Multi-Objective Evolutionary Algorithm for SSSC-Based Controller Design", Electric Power System Research, Vol. 79, Issue 6, pp. 937-944, 2009.

[10] Sidhartha Panda, "Differential Evolutionary Algorithm for TCSC-Based Controller Design", Simulation Modelling Practice and Theory, Vol. 17, pp. 16181634, 2009.

[11] Sidhartha Panda, "Multi-objective Non-Dominated Shorting Genetic Algorithm-II for Excitation and TCSC-Based Controller Design", Journal of Electrical Engineering, Vol. 60, No. 2, pp. 87-94, 2009.

[12] Sidhartha Panda, N.P. Padhy, "Comparison of Particle Swarm Optimization And Genetic Algorithm for FACTS-Based Controller Design”, Applied Soft Computing, Vol. 8, Issue 4, pp. 1418-1427, 2008.

[13]M. Nambu and Y. Ohsawa, "Development of an advanced power system stabilizer using a strict linearization approach", IEEE Transactions on Power Systems, Vol. 11, pp. 813-818, 1996.

[14]E. V. Larsen and D. A. Swann "Applying Power System Stabilizers Part II: Performance Objectives and 
IOSR Journal of Engineering

Apr. 2012, Vol. 2(4) pp: 810-813

Tuning Concepts', IEEE Transactions on Power Apparatus and Systems, Vol. 100, pp. 3025-3033, 1981.

[15]N. Tambey, M.L Kothari, "Unified Power Flow Controller (UPFC) Based Damping Controllers for Damping Low Frequency Oscillations in a Power System”, IE(I) Journal-EL, Vol. 84, pp. 35-41, 2003.

[16] M. E. About-Ela, A. A. Sallam, J. D. McCalley and A. A. Fouad, "Damping controller design for power system oscillations using global signals', IEEE Transactions on Power Systems, Vol. 11, pp. 767-773, 1996.

[17]D. E. Goldberg, Genetic Algorithms in Search, Optimization and Machine Learning. Addison-Wesley, 1989.

[18] Sidhartha Panda, A.K. Baliarsingh, R.K. Sahu, "Multiobjective Optimization Technique for TCSC-Based Supplementary Damping Controller Design", Proceedings World Congress on Nature \& Biologically Inspired Computing (NaBIC 2009), $21^{\text {st }}-23^{\text {rd }}$ Dec., 2009 Bhubaneswar, India., pp. 1065-1070, 2009.

[19] Sidhartha Panda, C. Ardil, "Real-Coded Genetic Algorithm for Robust Power System Stabilizer
Design", International Journal of Electrical, Computers and System Engineering, Vol. 2, No. 1, pp. 6-14, 2008.

[20] Sidhartha Panda, S.C. Swain, A.K. Baliarsingh, "RealCoded Genetic Algorithm for Robust Coordinated Design Of Excitation And SSSC-Based Controller", Journal of Electrical Engineering, Vol. 8, Issue 4, pp. 31-38, 2008.

[21] S. Panda, S.C. Swain, A.K. Baliarsingh, C. Ardil, "Optimal Supplementary Damping Controller Design For TCSC Employing RCGA", International Journal of Computational Intelligence, Vol. 5, No. 1, pp. 36-45, 2009.

[22] H F Wang. 'A Unified Model for the Analysis of FACTS Devices in Damping Power System Oscillations - Part III : Unified Power Flow Controller.' IEEETransactions on Power Delivery, Vol. 15, no 3, July 2000, p 978.

[23] N. Tambey, M.L Kothari, "Damping of Power System Oscillations with Unified Power Flow Controller (UPFC)", IEE Proc. Gener. Trans. Distrib., Vol. 150, No. 2, pp. 129-140, 2003. 